\title{
CD24 expression as a marker for predicting clinical outcome and invasive activity in uterine cervical cancer
}

\author{
TOMOHITO TANAKA, YOSHITO TERAI, YUHEI KOGATA, KEISUKE ASHIHARA, KAZUYA MAEDA, \\ SATOE FUJIWARA, SAHA YOO, YOSHIMICHI TANAKA, SATOSHI TSUNETOH, HIROSHI SASAKI, \\ MASANORI KANEMURA, AKIKO TANABE and MASAHIDE OHMICHI
}

Department of Obstetrics and Gynecology, Osaka Medical College, Takatsuki, Osaka 569-8686, Japan

Received May 31, 2015; Accepted July 8, 2015

DOI: $10.3892 /$ or.2015.4257

\begin{abstract}
CD24, a small heavily glycosylated mucin-like glycosyl-phosphatidylinositol-anchored cell surface protein, plays an important role in the carcinogenesis of various human malignancies. However, its function in cervical cancer remains unclear. The aim of the present study was to evaluate the expression of CD24 clinicopathologically and to analyze its functional behavior biologically in cervical cancer. A total of 117 uterine cervical cancer tumors were immunohistochemically analyzed using a CD24 monoclonal antibody on paraffin blocks. We also examined whether CD24 enhanced the invasive activity or the Akt, ERK, NF-KB and MMP activity in a uterine cervical cancer cell line (CaSki) by a western blot analysis. The patients with enhanced CD24 expression had a higher rate of advanced clinical stage (50 vs. $16.5 \%, \mathrm{p}<0.01$ ), lymph node metastasis ( 34.6 vs. $14.3 \%$ ) and lymphovascular involvement (65.4 vs. $20.4 \%, \mathrm{p}=0.01)$, and a poor overall and disease-free survival (5-year survival rate: 62 vs. $86 \%, \mathrm{p}=0.03$ ). $\mathrm{CD} 24$ overexpression in CaSki cells resulted in activation of Cell Signaling proteins, including Akt, ERK, NF- $\kappa \mathrm{B}$ and MMP-9. An invasion assay showed that CD24 overexpression in CaSki cells led to increased invasion ability. The CD24 overexpression also increased mRNA expression of Slug but not Snail. Moreover, the CD24 overexpression also decreased expression of E-cadherin and increased $\mathrm{N}$-cadherin protein levels. Increased expression of CD24 may be associated with
\end{abstract}

Correspondence to: Dr Yoshito Terai, Department of Obstetrics and Gynecology, Osaka Medical College, 2-7, Daigaku-machi, Takatsuki, Osaka 569-8686, Japan

E-mail: y-terai@poh.osaka-med.ac.jp

Abbreviations: CD24, cluster of differentiation 24; FIGO, International Federation of Gynecology and Obstetrics; RT-PCR, reverse transcription-polymerase chain reaction; EMT, epithelial to mesenchymal transition; MAPK, mitogen-activated protein kinase; $\mathrm{NF}-\kappa \mathrm{B}$, nuclear factor- $\kappa \mathrm{B}$; ERK, extracellular signal-regulated kinase; MMP, matrix metalloproteinase

Key words: uterine cervical cancer, CD24, lymph node metastasis, lymphovascular involvement, epithelial to mesenchymal transition, Slug, Akt, extracellular signal-regulated kinase, nuclear factor- $\kappa \mathrm{B}$ tumor progression and prognosis in patients with uterine cervical cancer. CD24 expression may therefore be used not only as a prognostic marker in uterine cervical cancer, but also as a target for the development of new therapeutic approaches.

\section{Introduction}

Cervical cancer of the uterus remains one of the major causes of cancer-related death in women worldwide. The global cervical cancer incidence has increased $0.6 \%$ annually from 1980 to 2010 , and the disease resulted in the death of 200,000 women in 2010 in developing countries (1). Despite the comparatively favorable survival for early-stage patients, numerous patients develop localized recurrence or distant metastases after initial treatment. As the potential targets for diagnosis and treatment of the cancer, molecules involved in cancer development, metastasis and outcome should be identified and functionally characterized.

Cluster of differentiation (CD) 24 is a small, heavily glycosylated mucin-like cell surface protein (27 amino acids in length) that binds to the membrane via a glycosyl-phosphatidylinositol anchor (2). Under physiological conditions, CD24 was initially identified as a B cell marker (3). Later, it was found to be expressed not only in developing or regenerating tissue, but also in granulocytes, pre-B cells, keratinocytes and renal tubules (4). CD24 has also been reported to be a ligand for P-selectin, an adhesion receptor on activated endothelial cells and platelets $(5,6)$, thus suggesting that the molecule functionally enhances the metastatic potential of cancer cells. Under pathological conditions, CD24 plays an important role in the carcinogenesis of various human malignancies. Its expression has been detected not only in hematologic malignancies (7), but also in various solid tumors, including retinoblastoma, glioma, laryngeal squamous cell and nasopharyngeal carcinoma, small cell lung and breast cancer, renal cell, hepatocellular and gallbladder carcinoma, pancreatic adenocarcinoma, colorectal and epithelial ovarian cancer, and bladder carcinoma (8-14). These studies demonstrated that CD24 overexpression was markedly associated with a more aggressive course of the disease. However, the correlation of CD24 expression with uterine cervical cancer, the underlying mechanisms and its prognostic significance still remain unknown. 
The present study was performed to evaluate the expression of CD24 clinicopathologically and to biologically analyze its functional behavior in uterine cervical cancer.

\section{Materials and methods}

Patients and tissue samples. The present study included 117 patients with stage Ib-IIb cervical cancer who were treated at the Osaka Medical College between 2002 and 2012. Patients were eligible for inclusion in the present study when they met the following criteria: i) they had undergone radical or modified radical hysterectomy and pelvic lymphadenectomy as an initial treatment; and ii) they had sufficient clinical data regarding the oncologic outcome including the date of recurrence. All patients were staged according to the International Federation of Gynecology and Obstetrics (FIGO) criteria. The histological subtype was assigned according to the criteria of the World Health Organization classification. The patients with FIGO stage IB and lymph node metastasis or lymphovascular space involvement, or deep half cervical stromal invasion, and all patients with FIGO stage II received postoperative adjuvant therapy involving entire pelvic irradiation and/or chemotherapy. Patients receiving primary radiotherapy/concurrent chemoradiation therapy without surgery or receiving any preoperative treatment were excluded from the present study. The Institutional Review Board approved the present study and informed consent was obtained from all patients for the use of their tissue samples.

Immunohistochemistry. Specimens were fixed in 10\% formalin and embedded in paraffin. Serial sections were cut from paraffin-embedded blocks and were used for routine histopathology. A 4- $\mu \mathrm{m}$ section was cut from a tissue microarray block and immunohistochemically analyzed for the expression of CD24. Deparaffinized and rehydrated sections $(4-\mu \mathrm{m})$ were autoclaved in $0.01 \mathrm{M}$ citrate buffer ( $\mathrm{pH} 6.0$ ) for $15 \mathrm{~min}$ at $121^{\circ} \mathrm{C}$ for antigen retrieval. The endogenous peroxidase activity was blocked with $0.3 \%$ solution hydrogen peroxide in methanol for $30 \mathrm{~min}$. Tumor sections were incubated at $4^{\circ} \mathrm{C}$ for $12 \mathrm{~h}$ with the CD24-specific antibodies (clone SN3b; 1:50 dilution; Thermo Fisher Scientific, Waltham, MA, USA). The sections were washed with $1 \mathrm{X}$ phosphate-buffered saline (PBS) and incubated with Histofine Simple Stain MAX-PO (Multi; Nichirei) for $30 \mathrm{~min}$ at room temperature. Finally, the sections were washed with $1 \mathrm{X}$ PBS and then were visualized by incubation with $\mathrm{H}_{2} \mathrm{O}_{2}$ /diaminobenzidine substrate solution for $5 \mathrm{~min}$. The sections were counterstained with hematoxylin prior to dehydration and mounting. The evaluation of the immunohistochemical data was performed by two independent pathologists who were blinded to the clinicopathological data. The expression of CD24 was assessed using a semi-quantitative system that was defined as described by Blechschmidt et al (15). Briefly, CD24 expression was scored as: 0 (no stain), $1+$ (weak immunoreactivity in $>10 \%$ of tumor cells), $2+$ (moderate immunoreactivity of $>10 \%$ of tumor cells), and $3+$ (strong immunoreactivity of $>10 \%$ of tumor cells). These data were summarized into two groups; low CD24 expression $(0,1+$, and $2+)$ and high CD24 expression (3+). Scoring was performed three times per slide for three distinct fields, and the three scores were then averaged.
Cell culture. The human cervical cancer CaSki cell line was obtained from the American Type Culture Collection (ATCC; Rockville, MD, USA) and grown in phenol red-free Dulbecco's modified Eagle's medium (DMEM) (Gibco) containing 10\% dextran-coated, charcoal-treated fetal calf serum, $100 \mathrm{U} / \mathrm{ml}$ penicillin and $100 \mu \mathrm{g} / \mathrm{ml}$ streptomycin in a humidified atmosphere of $5 \% \mathrm{CO}_{2}$ with $95 \%$ air at $37^{\circ} \mathrm{C}$.

Expression plasmids and cDNA transfection. To create the pcDNA3.1-CD24 expression construct, the cDNA of the full length CD24 was amplified by PCR using a human mammary gland cDNA library as the template. For the transfection of each sample, oligomer-Lipofectamine Plus complexes were prepared as follows: 100 pmol of cDNA oligomer were diluted in $250 \mu \mathrm{l}$ of Opti-MEM (Invitrogen). The Lipofectamine Plus was mixed gently before use, and then a $5 \mu 1$ aliquot was diluted in $250 \mu 1$ of Opti-MEM, were gently mixed and were incubated for $5 \mathrm{~min}$ at room temperature. After the $5 \mathrm{~min}$ incubation, the diluted oligomer was combined with the diluted Lipofectamine Plus, mixed gently and incubated for another $20 \mathrm{~min}$ at room temperature. The oligomer-Lipofectamine Plus complexes were added to each well containing cells and medium and mixed gently by rocking the plate back and forth. The cells were incubated at $37^{\circ} \mathrm{C}$ in a $\mathrm{CO}_{2}$ incubator for $24 \mathrm{~h}$, and then the cells were prepared for each assay.

RNA extraction and semi-quantitative reverse transcription-polymerase chain reaction (RT-PCR). We isolated total RNA from $1 \times 10^{6}$ transfected CaSki cells using a commercially available kit (Qiagen). We exposed the RNA samples to DNase digestion before the cDNA synthesis. For gene-specific PCR, $1 \mu \mathrm{l}$ of first-strand cDNA product was amplified with Platinum Taq Polymerase (Invitrogen) according to the manufacturer's instructions. We designed primers specific for CD24 (forward, 5'-ACCCACGCAGATTTATTCCA-3' and reverse, 5'-ACCA CGAAGAGACTGGCTGT-3'); for Snail (forward, 5'-GCCTT CAACTGCAAATACTGC-3' and reverse, 5'-CTTCTTGA CATCTGAGTGGGTC-3'); for Slug (forward, 5'-AGCTACC CAATGGCCTCTCT-3' and reverse, 5'-CCAGCCCAGAAAA AGTTGAA-3'); and for $\beta$-actin (forward, 5'-TGAGCGCGGC TACAGCTT-3' and reverse, 5'-TCCTTAATGTCACGCACGA TTT-3') and performed a 27-cycle, three-step PCR (denaturation at $94^{\circ} \mathrm{C}$ for $30 \mathrm{sec}$, annealing at $54^{\circ} \mathrm{C}$ for $30 \mathrm{sec}$, extension at $72^{\circ} \mathrm{C}$ for $30 \mathrm{sec}$ ) with an initial temperature of $94^{\circ} \mathrm{C}$ for $3 \mathrm{~min}$.

Western blot analysis. After transfection, cells were washed twice with ice-cold PBS, lysed and separated to cytoplasmic and nuclear fractions using the Nuclear Extract kit according to the manufacturer's instructions (Active Motif, Carlsbad, CA, USA). To detect Akt, phosphorylated Akt, ERK, phosphorylated ERK, NF- $\kappa B$, phosphorylated NF- $\mathrm{BB}$ and MMP-9 proteins we separated these by SDS polyacrylamide gel electrophoresis and electrotransferred to nitrocellulose membranes and transferred proteins to a membrane. Western blot analyses were performed with various specific primary antibodies including Akt (9272), phospho-Akt (Ser473; 9271), NF-кB (3034), phospho-NF-kB (Ser536; 3033), p44/42 MAP kinase (Erk; 4695), phospho-p44/42 MAP kinase (p-Erk; 9101), MMP-9 (2270), $\beta$-actin (4970), E-cadherin (3195) (all 
Table I. Clinicopathological characteristics of the patients with cervical cancer.

\begin{tabular}{|c|c|c|c|c|}
\hline $\begin{array}{l}\text { Expression of CD24 protein } \\
\text { Factor }\end{array}$ & Value & Reduced (\%) & Preserved $(\%)$ & P-value \\
\hline No. of patients & 117 & $91(77.8)$ & $26(22.2)$ & \\
\hline Mean age (years) & $51.0 \pm 11.5$ & & & \\
\hline \multicolumn{5}{|l|}{ Stage classification } \\
\hline $\mathrm{Ib}$ & $89(76.1)$ & $76(83.5)$ & $13(50.0)$ & \\
\hline II & $28(23.9)$ & $15(16.5)$ & $13(50.0)$ & $<0.01$ \\
\hline \multicolumn{5}{|l|}{ Histological type } \\
\hline Squamous cell carcinoma & $76(68.1)$ & $61(67.0)$ & $15(57.7)$ & \\
\hline Adenocarcinoma & $41(31.9)$ & $30(33.0)$ & $11(42.3)$ & 0.5 \\
\hline \multicolumn{5}{|l|}{ Lymph node metastasis } \\
\hline Negative & $95(81.2)$ & $78(85.7)$ & $17(65.4)$ & \\
\hline Positive & $22(18.8)$ & $13(14.3)$ & $9(34.6)$ & 0.03 \\
\hline \multicolumn{5}{|l|}{ Lymphovascular involvement } \\
\hline Negative & $79(67.5)$ & $70(79.6)$ & $9(34.6)$ & \\
\hline Positive & $38(32.5)$ & $21(20.4)$ & $17(65.4)$ & $<0.01$ \\
\hline \multicolumn{5}{|l|}{ Recurrence } \\
\hline Negative & $98(83.8)$ & $81(89.0)$ & $17(65.5)$ & \\
\hline Positive & $19(16.2)$ & $10(11.0)$ & $9(34.6)$ & $<0.01$ \\
\hline Mean follow-up (months) & $41.5 \pm 27.3$ & & & \\
\hline
\end{tabular}

from Cell Signaling, Danvers, MA, USA) and N-Cadherin (ab18203; Abcam, Cambridge, MA, USA). The immunoreactive bands in the immunoblots were visualized with horseradish peroxidase-coupled goat anti-rabbit immunoglobulin using an enhanced chemiluminescence western blotting system (ECL Plus; GE Healthcare Life Sciences, Pittsburgh, PA, USA). Non-specific antigen sites were blocked with $10 \%$ bovine serum albumin in $1 \mathrm{X}$ Tris-buffered saline.

Migration and invasion assays. We examined the effects of CD24 on the invasive potential of CaSki cells by an invasion assay. CaSki cells $\left(5 \times 10^{5}\right.$ cells) were cultured at $37^{\circ} \mathrm{C}$ in a humidified, $5 \% \mathrm{CO}_{2}$ atmosphere incubator in serum-free DMEM for $24 \mathrm{~h}$, seeded into the upper wells and coated with a thin layer of Matrigel. The lower chamber contained $600 \mu \mathrm{l}$ of DMEM. Following a 24 -h incubation at $37^{\circ} \mathrm{C}$, non-invading cells on the surface of the Matrigel-coated membrane were removed by scraping with a cotton swab. The cells that migrated through the Matrigel were stained with hematoxylin. Following several washes with PBS, the stained cells were manually counted for three independent experiments. Each point represents the mean \pm SD of four replicates.

Statistical analysis. Statistical analyses in the present study were performed with the JMP statistical software package (version. 9.0.2). Fisher's exact probability test was used for evaluating correlations between the immunohistochemical and clinical data. The end points investigated were the progressionfree (PFS ) and overall survival (OS) rates, respectively). The PFS was defined as the time from the first day of treatment until either death from any cause or disease progression. OS was defined as the time from the first day of treatment to death from any cause. Univariate analyses of the PFS and OS were determined with the Kaplan-Meier method using a log-rank test. The Mann-Whitney U test was used for the comparison of continuous variables. The continuous variables ae expressed as the means \pm SD by an analysis of the variance (ANOVA) when the variance of the samples showed a normal standard distribution. They were expressed as the median with interquartile ranges when the variance did not show a normal standard distribution. Statistical significance was considered to be present at p-values of $<0.05$.

\section{Results}

Clinicopathological characteristics. A total of 117 patients with uterine cervical cancer were enrolled in the present study. Table I shows the characteristics of the patients. The mean ( \pm SD) age of the patients was $51.0 \pm 11.5$ years. Eighty-nine (76.1\%) patients were of FIGO stage Ib and 28 (23.9\%) were stage II. Histologically, $76(68.1 \%)$ patients had squamous cell carcinoma and 41 (31.9\%) patients had adenocarcinoma. Twenty-two (18.8\%) patients had lymph node metastasis and $38(32.5 \%)$ had lymphovascular involvement. Cervical cancer recurrence developed in $19(16.2 \%)$ of the 117 patients. The median follow-up was $41.5 \pm 27.3$ months. CD24 was mainly localized in the cytoplasm and on the membranes of tumor cells (Fig. 1). A high CD24 expression was observed in the tumors from $26(22.2 \%)$ patients. The staining pattern [low (negative, weak or moderate) or high (strong)] is shown in Fig. 1. 
Low CD24 expression

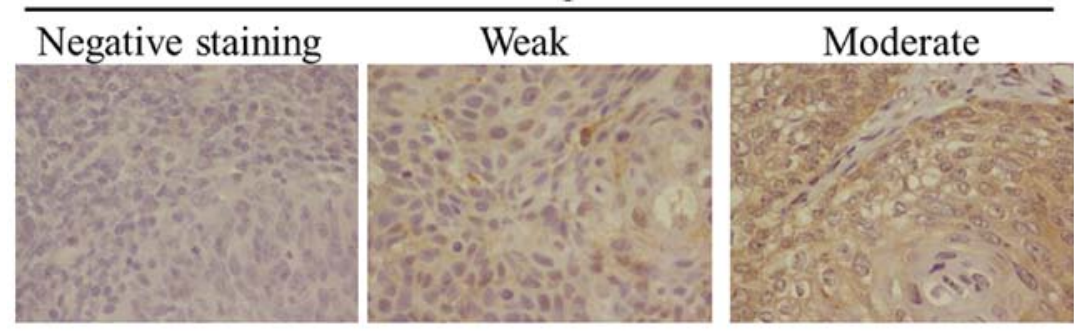

High CD24 expression

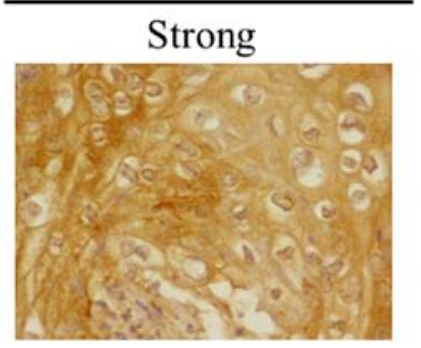

Figure 1. CD24 expression in cervical cancer tissue. Immunohistochemical staining was performed and representative cases, including cases with reduced (negative, weak and moderate) and preserved (strong) expression are shown.
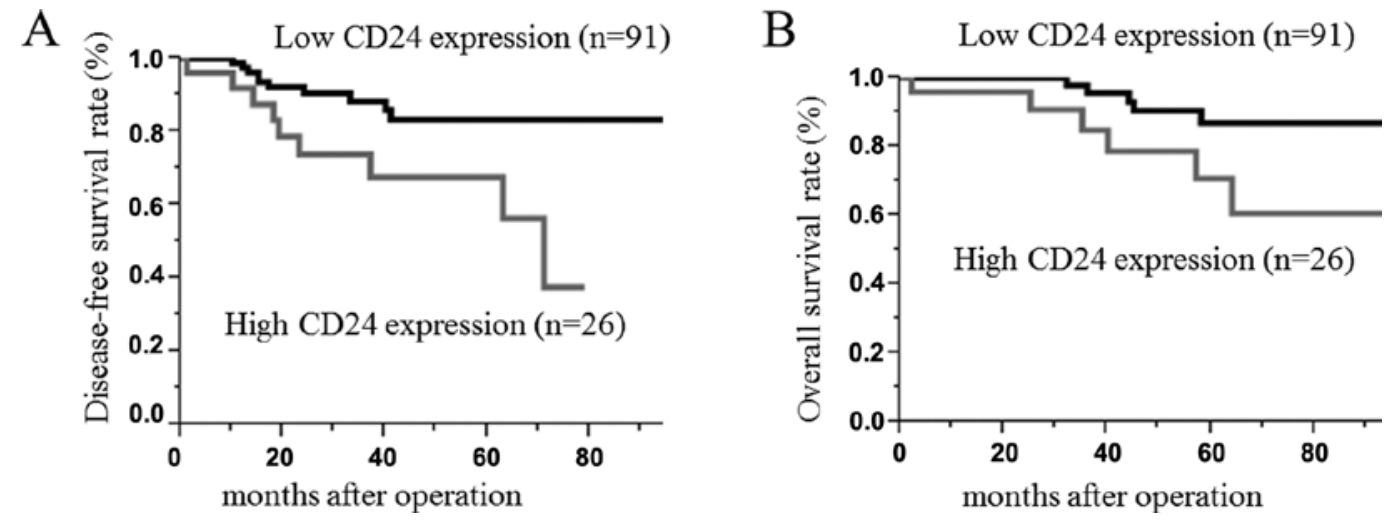

Figure 2. (A) Disease-free and (B) overall survival curves for two groups defined by reduced and preserved expression of CD24 in patients with cervical cancer. The patients with preserved CD24 expression had significantly worse 5-year disease-free and overall survival rates than those with reduced CD24 staining (both $\mathrm{p}<0.01$ ).

Association of CD24 expression with clinicopathological parameters of cervical cancer. Immunohistochemically, 28 (23.9\%) patients had tumors with high CD24 expression. Among 91 (77.8\%) patients with low CD24 expression tumors, $35(29.9 \%)$ had negative, $30(25.6 \%)$ had weak and $26(22.2 \%)$ had moderate staining. The patients with tumors that expressed high CD24 levels had a higher rate of advanced clinical stage (50 vs. $16.5 \%, \mathrm{p}<0.01)$, lymph node metastasis $(34.6$ vs. $14.3 \%$ ), lymphovascular involvement (65.4 vs. $20.4 \%$, $\mathrm{p}=0.01)$ and recurrence rate of cervical cancer (34.6 vs. $11.0 \%$, $\mathrm{p}<0.05$ ) (Table I).

Correlation between CD24 expression and prognosis. The survival rate and disease-free survival rate of the cervical cancer following surgical treatment were analyzed using the Kaplan-Meier method. The median follow-up time for all patients was $41.5 \pm 27.3$ months. The survival rate was determined from the day of the initial surgery to the time of the death or the last follow-up. The disease-free survival rate was determined from the day of the initial surgery to the time of the detection of cancer recurrence, death or the last follow-up. The 5-year disease-free survival rates of cervical cancer in patients with high and low CD24 expression tumors were 62 and $86 \%$, respectively. The 5-year OS rates of cervical cancer in patients with high and low CD24 expression tumors were 62 and $86 \%$, respectively. The log-rank test analyses revealed a statistically significant difference between the two groups (p<0.01) (Fig. 2).

CD24 specifically enhances the cell invasion through Matrigel in human squamous cervical cancer cells. In recent studies, CD24 was shown to play an important role in the development and progression of malignant tumors (16). We examined whether CD24 regulates invasive activity in uterine cervical cancer. To assess this possibility, we transiently transfected the CD24 gene into a cervical cancer cell line (CaSki cells). 
A
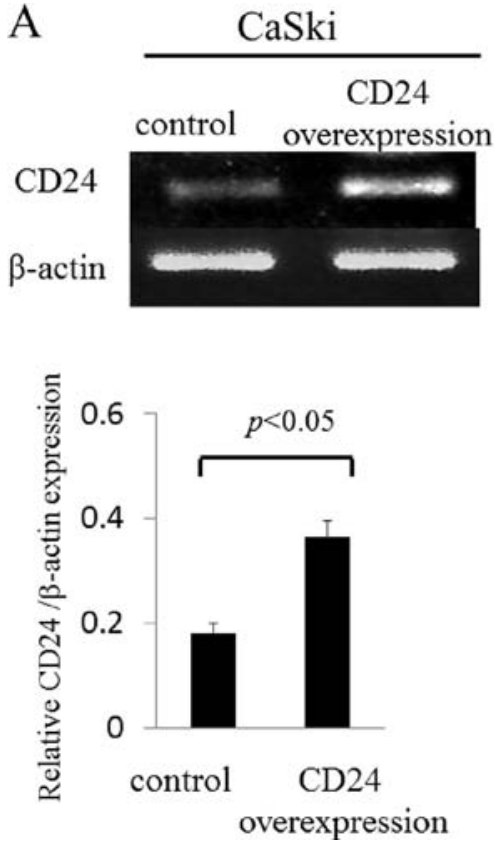

B
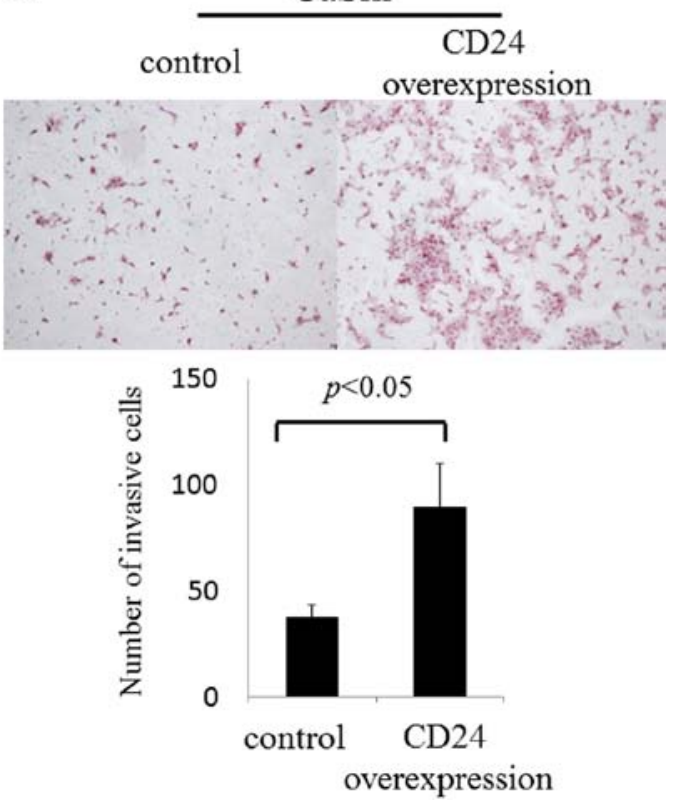

Figure 3. Matrigel invasion assay. (A) The recombinant vector pcDNA6.2/V5-CD24 (pcDNA-CD24) containing CD24 ORF or the empty vector pcDNA6.2/V5 (pcDNA) was transfected into CaSki cells using Lipofectamine 2000. The results showed that CD24 was successfully overexpressed in pcDNA6.2/V5-CD24transfected cells. (B) CD24-transfected CaSki cells were seeded in a Matrigel-coated upper chamber. Cell invasion through the Matrigel after incubation for $16 \mathrm{~h}$ was detected by H\&E staining and quantified. Data are expressed as the mean $\pm \mathrm{SD}, \mathrm{n}=3$ in triplicate. H\&E, hematoxylin and eosin.

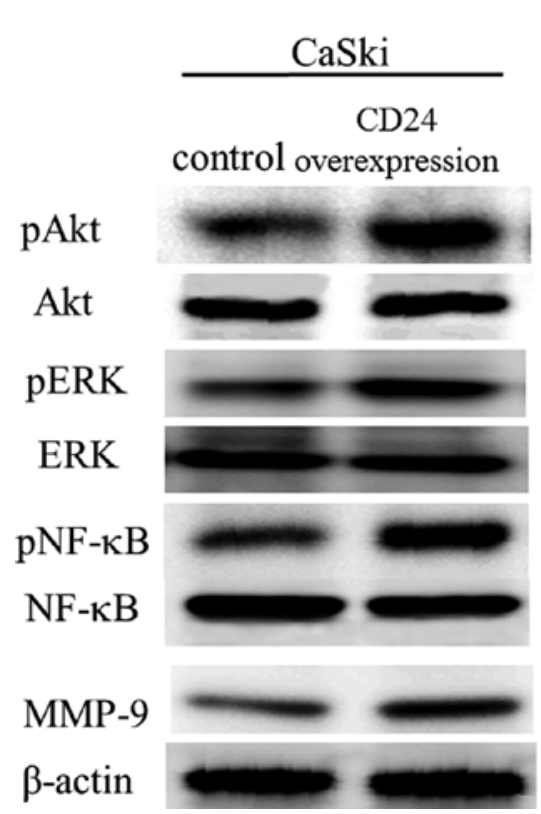

pAkt

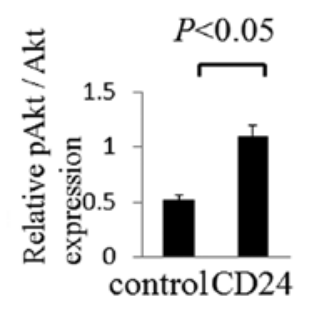

pNF- $\mathrm{kB}$

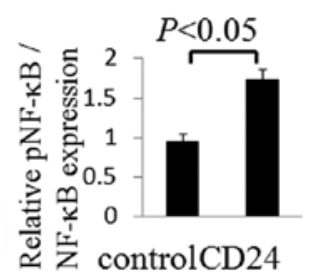

pERK

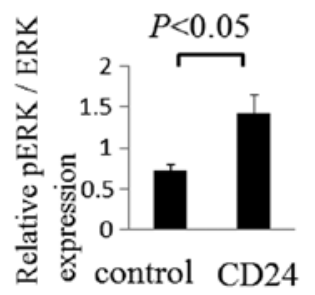

MMP-9

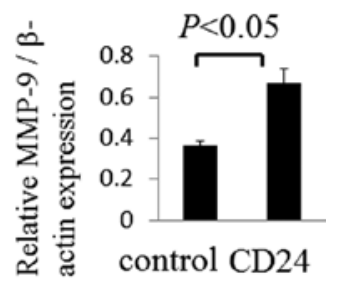

Figure 4. Western blot analyses. CD24-transfected CaSki cells showed an increase in the phosphorylation of AkT, ERK and NF- $\mathrm{kB}$ and the activation of MMP-9. The differences were statistically significant $(\mathrm{p}<0.05)$.

The mRNA expression of CD24 in CaSki cells was evaluated by semi-quantitative RT-PCR (Fig. 3). The mRNA expression level of $C D 24$ in CaSki cells that were transfected with the CD24 gene was found to be upregulated by 2.0 -fold when compared to the control group $(0.36 \pm 0.03$ vs. $0.18 \pm 0.02$; $\mathrm{p}<0.05)$ (Fig. 3A). The sensitivity of the invasive activity of $\mathrm{CD} 24$ in the CaSki cells was examined using an invasion assay which monitors cell migration Matrigel. The overexpression of CD24 significantly increased the migration and invasion of
CaSki cells by 2.0 -fold through the Matrigel $(89.2 \pm 20.8$ vs . 37.1 \pm 6.5 , p<0.05) (Fig. 3B).

CD24 signaling enhances Akt and MAPK-ERK1/2 signaling in human squamous cervical cancer cells. We established that in CaSki cells, phosphorylation of Akt and MAPK-ERK1/2 were induced by CD24 through western blot analysis. The phosphorylation of Akt was found to be upregulated by 2.1-fold in the overexpression of $\mathrm{CD} 24$ group when compared 
A

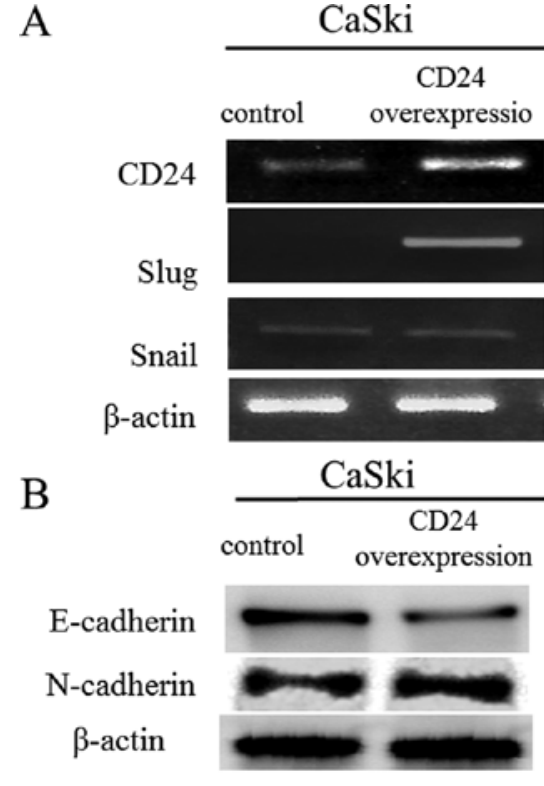

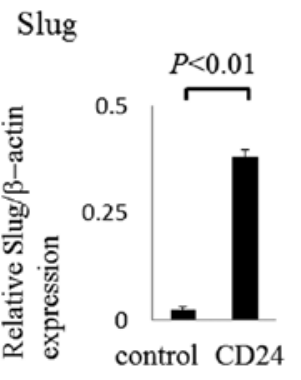

Snail

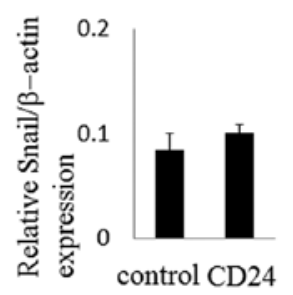

E-cadherin

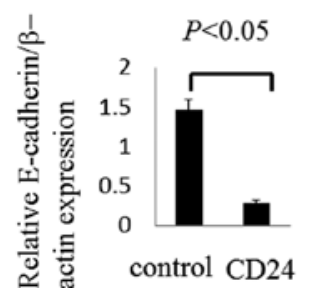

N-cadherin

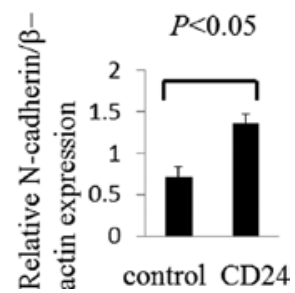

Figure 5. Expression of Slug, Snail, E-cadherin and N-cadherin in transfected CaSki cells overexpressing CD24. (A) We observed an increase in Slug mRNA levels in CD24-transfected CaSki cells (p<0.01), yet the effects on Snail were not significant. (B) CD24-transfected CaSki cells also expressed decreased E-cadherin and increased N-cadherin $(\mathrm{p}<0.05)$.

to the control group $(1.09 \pm 0.10$ vs. $0.52 \pm 0.05 ; \mathrm{p}<0.05)$ (Fig. 4). The phosphorylation of ERK was also found to be upregulated by 2.0 -fold in the overexpression of CD24 group compared to be the control group $(1.42 \pm 0.23$ vs. $0.72 \pm 0.08 ; \mathrm{p}<0.05)$. Next, we examined the phosphorylation of $\mathrm{NF}-\kappa \mathrm{B}$ and the MMP-9 activity following the overexpression of CD24, as the overexpression of CD24 significantly increased the migration and invasion of CaSki cells through the Matrigel. The phosphorylation of $\mathrm{NF}-\kappa \mathrm{B}$ was found to be upregulated by 1.8-fold in the overexpression of CD24 in CaSki cells compared to the control group $(1.74 \pm 0.13$ vs. $0.95 \pm 0.09 ; \mathrm{p}<0.05)$ (Fig. 4). In addition, the activation of MMP-9 was found to be upregulated by 1.8 -fold in the overexpression of $\mathrm{CD} 24$ group compared to the control group $(0.67 \pm 0.07$ vs. $0.37 \pm 0.02 ; \mathrm{p}<0.05)$ (Fig. 4).

CD24 associates with epithelial to mesenchymal transition (EMT) signaling via Slug in human squamous cervical cancer cells. In recent studies, CD24-positive cells were shown to be susceptible to the induction of EMT, a phenotype important for cancer metastasis in ovarian, breast, and pancreas carcinomas (4,17-20). We examined whether CD24 regulates the expression of Slug or Snail in uterine cervical cancer. To assess this possibility, we transiently transfected the CD24 gene into a cervical cancer cell line (CaSki cells). The mRNA expression of Slug in CaSki cells that were transfected with the CD24 gene was found to be upregulated by 16.5 -fold according to semi-quantitative RT-PCR compared to the control group $(0.38 \pm 0.01$ vs. $0.02 \pm 0.007 ; \mathrm{p}<0.05)$ (Fig. $5 \mathrm{~A})$, although the effects on the expression of Snail were not significant. Moreover, the expression of E-cadherin in the CD24 overexpression cells was found to be downregulated by 0.2 -fold by a western blot analysis compared to the control group $(0.28 \pm 0.05$ vs. $1.47 \pm 0.14 ; \mathrm{p}<0.05)$, and the expression of $\mathrm{N}$-cadherin in the CD24 overexpression cells was found to be upregulated by 2.0 -fold by a western blot analysis compared to the control group (1.37 \pm 0.1 vs. $0.71 \pm 0.13$; $\mathrm{p}<0.05)$ (Fig. $5 \mathrm{~B})$.

\section{Discussion}

We concluded that the present results indicate that enhanced CD24 expression in cervical cancer was significantly correlated with aggressive clinicopathological features. Furthermore, CD24 overexpression appears to results in an enhanced invasive potential of uterine cervical cancer cells through the activation of both Akt and ERK1/2 signaling cascades. Additionally, we showed that CD24-induced invasive potential correlated with the EMT phenomenon in uterine cervical cancer.

CD24 has been considered to be involved in the process of tumor metastasis and invasion as the ligand of P-selectin and the adhesion receptor in activated endothelial cells and platelets (21). Many cancer cells can bind to platelets via CD24-mediated binding to P-selectin, which facilitates the exit of cancer cells from the bloodstream and enhance the metastatic potential of cancer cells (22). CD24 has been identified as a marker of cancer stem cells in various human malignancies, such as pancreatic, breast, colorectal, gastrointestinal tract and liver cancers (23-26). Several immunohistochemical studies previously demonstrated that CD24 overexpression is associated with clinicopathological features, such as the pathological grade, lymph node metastasis and subsequent poor prognosis of various types of cancers $(11,13,14,27,28)$. Furthermore, various studies showed that CD24 overexpression contributes to cell proliferation and invasiveness in vitro (11). In line with these previous studies, our data demonstrated that enhanced CD24 was associated with advanced clinical stage, lymph node metastasis, lymphovascular involvement and poor prognosis in patients with uterine cervical cancer. Additionally, CD24 overexpression in a cervical cancer cell line (CaSki) led to increased invasiveness. Our data further demonstrated that CD24 contributes to the invasiveness through the phosphorylation of Akt, NF- $\kappa \mathrm{B}$ and ERK and the activation of MMP-9. 
Conversely, during the progression of epithelial cancer, cells typically lose the characteristic features of epithelial cells and gain a mesenchymal phenotype. EMT has been implicated in the metastasis of primary tumors and provides a molecular mechanism (29). One of the most well-defined features of EMT is the loss of E-cadherin expression (30). A group of transcription factors, including Snail and Slug, have been implicated in the control of EMT (31). Cadherin switch, which indicates a decrease of E-cadherin and increase of $\mathrm{N}$-cadherin, is also essential for increased motility, yet is not always required for the morphological changes that accompany EMT (32). Previous studies have reported that CD24 promotes cell invasion and induce significant amounts of EMT-associated markers in ovarian and breast cancers $(4,21)$ In the present study, $\mathrm{CD} 24$ overexpression in CaSki cells led to the activation of Slug, a decrease of E-cadherin protein levels and an increase of $\mathrm{N}$-cadherin protein levels; thus, our data suggests that $\mathrm{CD} 24$ contributes to EMT through the activation of Slug in uterine cervical cancer, although we could not clarify whether Slug, via CD24, directly regulates the activity of Akt, NF- $\mathrm{BB}$ or ERK.

In conclusion, CD24 expression in cervical cancer was significantly correlated with aggressive clinicopathological features. Furthermore, CD24 overexpression led to enhanced invasive potential of uterine cervical cancer cells through the activation of both Akt and ERK1/2 signaling cascades. CD24 overexpression cancer cells additionally had enhanced invasive potential through the activation of both Akt and ERK1/2 signaling cascades and EMT-inducing pathways. CD24 expression may therefore not only be a potential prognostic marker in uterine cervical cancer, but also a target for the development of new therapeutic approaches.

\section{Acknowledgements}

The present study was supported by a JSPS KAKENHI, grant no. 25462621 (to Y.T.).

\section{References}

1. Forouzanfar MH, Foreman KJ, Delossantos AM, Lozano R Lopez AD, Murray CJ and Naghavi M: Breast and cervical cancer in 187 countries between 1980 and 2010: A systematic analysis. Lancet 378: 1461-1484, 2011.

2. Kay R, Rosten PM and Humphries RK: CD24, a signal transducer modulating $\mathrm{B}$ cell activation responses, is a very short peptide with a glycosyl phosphatidylinositol membrane anchor J Immunol 147: 1412-1416, 1991

3. Aigner S, Ruppert M, Hubbe M, Sammar M, Sthoeger Z, Butcher EC, Vestweber D and Altevogt P: Heat stable antigen (mouse CD24) supports myeloid cell binding to endothelial and platelet P-selectin. Int Immunol 7: 1557-1565, 1995.

4. Lee KM, Ju JH, Jang K, Yang W, Yi JY, Noh DY and Shin I CD24 regulates cell proliferation and transforming growth factor $\beta$-induced epithelial to mesenchymal transition through modulation of integrin $\beta 1$ stability. Cell Signal 24: 2132-2142, 2012.

5. Aigner S, Sthoeger ZM, Fogel M, Weber E, Zarn J, Ruppert M, Zeller Y, Vestweber D, Stahel R, Sammar M, et al: CD24, a mucin-type glycoprotein, is a ligand for P-selectin on human tumor cells. Blood 89: 3385-3395, 1997.

6. Sammar M, Aigner S and Altevogt P: Heat-stable antigen (mouse CD24) in the brain: Dual but distinct interaction with P-selectin and L1. Biochim Biophys Acta 1337: 287-294, 1997.

7. King JB, von Furstenberg RJ, Smith BJ, McNaughton KK, Galanko JA and Henning SJ: CD24 can be used to isolate Lgr5 putative colonic epithelial stem cells in mice. Am J Physiol Gastrointest Liver Physiol 303: G443-G452, 2012.
8. Li J, Li C, Yuan H and Gong F: Clinical value of CD24 expression in retinoblastoma. J Biomed Biotechnol 2012: 158084, 2012.

9. Deng J, Gao G, Wang L, Wang T, Yu J and Zhao Z: CD24 expression as a marker for predicting clinical outcome in human gliomas. J Biomed Biotechnol 2012: 517172, 2012.

10. Hira SK and Manna PP: Down regulation of CD24 and HER-2/neu in breast carcinoma cells by activated human dendritic cell. Role of STAT3. Cell Immunol 275: 69-79, 2012.

11. Shi Y, Gong HL, Zhou L, Tian J and Wang Y: CD24: A novel cancer biomarker in laryngeal squamous cell carcinoma. ORL J Otorhinolaryngol Relat Spec 74: 78-85, 2012.

12. Su N, Peng L, Xia B, Zhao Y, Xu A, Wang J, Wang X and Jiang B: Lyn is involved in CD24-induced ERK1/2 activation in colorectal cancer. Mol Cancer 11: 43, 2012.

13. Zhu J, Zhang G and Lu H: CD24, COX-2, and p53 in epithelial ovarian cancer and its clinical significance. Front Biosci 4: 2745-2751, 2012

14. Liu C, Zheng S, Shen H, Xu K, Chen J, Li H, Xu Y, Xu A, Chen B, Kaku H, et al: Clinical significance of CD24 as a predictor of bladder cancer recurrence. Oncol Lett 6: 96-100, 2013.

15. Blechschmidt K, Sassen S, Schmalfeldt B, Schuster T, Höfler H and Becker KF: The E-cadherin repressor Snail is associated with lower overall survival of ovarian cancer patients. Br J Cancer 98: 489-495, 2008.

16. Wang W, Wang X, Peng L, Deng Q, Liang Y, Qing H and Jiang B: CD24-dependent MAPK pathway activation is required for colorectal cancer cell proliferation. Cancer Sci 101: 112-119, 2010.

17. Kang KS, Choi YP, Gao MQ, Kang S, Kim BG, Lee JH, Kwon MJ, Shin YK and Cho NH: CD24+ ovary cancer cells exhibit an invasive mesenchymal phenotype. Biochem Biophys Res Commun 432: 333-338, 2013.

18. Lee SH, Kim H, Hwang JH, Shin E, Lee HS, Hwang DW, Cho JY, Yoon YS, Han HS and Cha BH: CD24 and S100A4 expression in resectable pancreatic cancers with earlier disease recurrence and poor survival. Pancreas 43: 380-388, 2014.

19. Zhang Y, Wei J, Wang H, Xue X, An Y, Tang D, Yuan Z, Wang F, Wu J,Zhang J, et al: Epithelial mesenchymal transition correlates with $\mathrm{CD} 24^{+} \mathrm{CD} 44^{+}$and $\mathrm{CD} 133^{+}$cells in pancreatic cancer. Oncol Rep 27: 1599-1605, 2012.

20. Lim J, Lee KM, Shim J and Shin I: CD24 regulates stemness and the epithelial to mesenchymal transition through modulation of Notch1 mRNA stability by p38MAPK. Arch Biochem Biophys 558: 120-126, 2014.

21. Jaggupilli A and Elkord E: Significance of CD44 and CD24 as cancer stem cell markers: An enduring ambiguity. Clin Dev Immunol 2012: 708036, 2012.

22. Newman H, Shapira S, Spierer O, Kraus S, Rosner M, Pri-Chen S, Loewenstein A, Arber N and Barak A: Involvement of CD24 in angiogenesis in a mouse model of oxygen-induced retinopathy. Curr Eye Res 37: 532-539, 2012.

23. Rasheed ZA and Matsui W: Biological and clinical relevance of stem cells in pancreatic adenocarcinoma. J Gastroenterol Hepatol 27 (Suppl 2): S15-S18, 2012.

24. Keysar SB and Jimeno A: More than markers: Biological significance of cancer stem cell-defining molecules. Mol Cancer Ther 9: 2450-2457, 2010.

25. Kemper K, Grandela C and Medema JP: Molecular identification and targeting of colorectal cancer stem cells. Oncotarget 1: 387-395, 2010.

26. Zou GM: Cancer initiating cells or cancer stem cells in the gastrointestinal tract and liver. J Cell Physiol 217: 598-604, 2008.

27. Tang J, Cai H, Lin L, Xie P, Zhong W and Tang M: Increased expression of CD24 is associated with tumor progression and prognosis in patients suffering osteosarcoma. Clin Transl Oncol 15: 541-547, 2013.

28. Wu JX, Zhao YY, Wu X and An HX: Clinicopathological and prognostic significance of CD24 overexpression in patients with gastric cancer: A meta-analysis. PLoS One 9: e114746, 2014.

29. Lee JM, Dedhar S, Kalluri R and Thompson EW: The epithelial-mesenchymal transition: New insights in signaling, development, and disease. J Cell Biol 172: 973-981, 2006.

30. Thiery JP, Acloque H, Huang RY and Nieto MA: Epithelialmesenchymal transitions in development and disease. Cell 139: 871-890, 2009.

31. Peinado H, Olmeda D and Cano A: Snail, Zeb and bHLH factors in tumour progression: An alliance against the epithelial phenotype? Nat Rev Cancer 7: 415-428, 2007.

32. Maeda M, Johnson KR and Wheelock MJ: Cadherin switching: essential for behavioral but not morphological changes during an epithelium-to-mesenchyme transition. J Cell Sci 118: 873-887, 2005. 